\title{
Well-being and engagement as predicted by fit and misfit of work to family supervisor interruption behaviors and - subordinate interruption tolerance
}

\author{
Mireia Las Heras Maestro \\ IESE Business School - Managing People in Organizations
}

Sowon Kim

Ecole hôtelière de Lausanne - University of Applied Sciences Western Switzerland

Pablo Ignacio Escribano

IESE Business School - Managing People in Organizations

Anneloes Raes

IESE Business School - Managing People in Organizations

Received October 21, 2016; accepted November 6, 2016.

\begin{abstract}
The purpose of our study is to examine the effects of alignment and misalignment between supervisor's work-to-family interruptive behaviors and subordinate's tolerance for such interruptions on the latter's well-being and engagement. Based on 582 supervisor-subordinate dyads, we find that alignment (the degree of similarity between the supervisor and subordinate) is not always significantly better than misalignment. In fact, our results show that when supervisor shows a low level of work-to-family interruptive behaviors while subordinate has a high tolerance for such interruptions increases subordinate's well-being and engagement. When supervisor shows a high level of work-to-family interruptive behaviors while subordinate has a low tolerance for such interruptions, subordinate's well-being and engagement decrease. Implications and future research directions are discussed.
\end{abstract}

\section{KEYWORDS}

Work-to-family interruption, boundary management, person-supervisor fit. 


\section{INTRODUCTION}

A growing body of the literature shows that work-family interruptions and tensions have grown over the past decades (Chinchilla, Las Heras, \& Masuda, 2009; Poelmans, Greenhaus, \& Las Heras, 2013). Simultaneously, the options to work in a more flexible manner (from alternative locations and at different times) have also grown exponentially. This all has resulted in employees who are potentially required to respond to communications and solve queries 24/7, who are better equipped to work from places other than the office, and who thus need to solve the dilemma of when, and to what extent, they let their job intrude in their family time (Kossek \& Lautsch, 2008; Sweet, 2014). The work-to-family interface is about time spent at work, work tempo, scheduling, autonomy and predictability among others. It specifically is about managing to what extent workto-family boundaries are permeable; specifically to what extent work intrudes into family time.

While some individuals are comfortable with such interruptions, others are not, as individuals differ in the degree to which they prefer to have their work and family life segmented or integrated (Nippert-Eng, 1996). Individuals who prefer to segment work and family life have a tendency to separate the two spheres and are more likely to be disturbed by interruptions than those who prefer to integrate. However, preferences might not always translate into actual behaviors. That is, how the work-family boundaries are managed might not only depend on what I prefer or the extent to which I can tolerate interruptions, but also on what is expected from me and what I am allowed to do or not do. In a work relationship, i.e., supervisors and subordinates, both persons might perceive and manage work-to-family interruptions in a similar (aligned) or dissimilar (misaligned) way.

Alignment refers to the degree of compatibility and similarity between the individual and his/her environment, represented by the job itself, the values of company or the supervisor's personality (Kristof, 1996). Alignment is widely accepted as being desirable due to its positive outcomes such as job performance, job satisfaction, organizational identification, citizenship behaviors and turnover decision (e.g., Bretz \& Judge, 1994; Cable \& DeRue, 2002; Jansen \& Kristof-Brown, 2006; Wang, Zhan, McCune, \& Truxillo, 2011). Yet, no study to our knowledge has examined the person-supervisor fit in the work-family context and specifically, how this (mis)fit might impact an individual's work and family life. 
The purpose of our study is to examine the effects of (mis)alignment between supervisors' actual behaviors of work-to-family interruption (hereby supervisor interruption behaviors) and subordinates' tolerance for such interruptions (hereby subordinate interruption tolerance) on subordinates' (a) well-being and (b) engagement. To do this, we build on the literature on boundary theory, as well as the literature on personenvironment fit. In this section, we pay special attention to distinguish the phenomenological approaches to fit and situate our study in the correct one. Second, we build on the literature on leader-follower (mis)fit, and based on boundary and fit theories, we draw hypotheses regarding the effects of supervisor-subordinate interruption management (mis)alignment. We then proceed to present our method and results and to discuss them. Finally, we offer practical implications, state the limitations and propose directions for future research.

The present study contributes to the literature by looking at a so far unexplored phenomenon, the fit between supervisor interruption behaviors and subordinate interruption tolerance, which promises to be a source of relevant insight for both research and practice on work-family interruptions. We do so using 582 supervisor-subordinate dyads belonging to two companies in El Salvador. Our results provide significant results, specifically on the consequences of misalignment, which may considerably enhance insights in the area of work-family research and have implications for managerial practices. 


\section{LITERATURE REVIEW, THEORY AND HYPOTHESES}

\subsection{Managing Work-to-Family Interruptions}

As postulated by boundary theory (Nippert-Eng, 1996), individuals draw boundaries between work and family life and manage them proactively (Ashforth, Kreiner, \& Fugate, 2000; Clark, 2000; Nippert-Eng, 1996). Role boundaries are physical, temporal, emotional, cognitive and/or relational limits that define those roles as separate from one another, thus delimiting its perimeter and scope (Ashforth, Kreiner, \& Fugate, 2000). The extent to which individuals are comfortable with, and allow interruptions from, one role intruding the other, depends on whether they prefer to segment or to integrate work and family life (e.g., Ashforth et al., 2000; Kreiner, Hollensbe, \& Sheep, 2009; Nippert-Eng, 1996).

Segmentors see the two roles as separated; they prefer keeping activities of each role within their respective boundaries (e.g., not solve personal issues at work); and they are capable of cognitively disconnecting (e.g., not think of work at home). Integrators see the two roles as interconnected; thus, they draw permeable and flexible boundaries between them (e.g., work at home, make personal calls at work). Research has failed to show that segmentors are more attracted toward companies offering segmenting policies, while integrators feel more attracted by companies offering integration policies (Bourhis \& Mekkaoui, 2010). However, it presents evidence that the desire for greater segmentation moderates the relationship between the organizational policies one has access to and an individual's satisfaction and commitment; specifically, people who want more segmentation are less satisfied and committed to the organization when they have greater access to integrating policies than when they have less access to such policies (Rothbard, Phillips, \& Dumas, 2005).

The extent to which individuals segment versus integrate is defined by the characteristics of the boundary, which can be described by their level of permeability and flexibility. A boundary is permeable when individuals are physically and cognitively present in one role and interrupt it to carry out an action that belongs to the other role — such as taking a phone call from a family member while being at work or sending an email to a doctor to make an appointment (Clark, 2000). A boundary is flexible when individuals want to leave one role to attend to the interruptions of another role, and are capable of doing so (Matthews \& Barnes-Farrell, 2010). Researchers have also shown that people can create 
their ideal level of segmentation or integration by using various tactics (Kreiner et al., 2009), suggesting that they are actively involved in boundary management.

Both segmenting and integrating boundaries have shown to have positive as well as negative consequences. Segmenting decreases work-family conflict, but also limits positive spillover. Integrating enhances positive, but also negative, spillover (e.g., Hecht $\&$ Allen, 2009). The primary benefit of segmenting is the reduced ambiguity and interruptions between domains; these benefits are actually the primary costs of integrating. The primary cost of segmenting is the increased difficulty to cross boundaries between the two domains; a reduced difficulty to cross boundaries is actually the primary benefit of integrating (Ashforth et al., 2000).

Individuals differ in the ways they manage their boundaries between work and family (Kreiner, Hollensbe, \& Sheep, 2009), as a result of individuals' variance in their preferences to segment or to integrate (Rothbard et al., 2005), and workplaces' variance in the extent to which an environment favors segmentation or integration (Hochschild, 1997; Kossek \& Lautsch, 2012; Kreiner, 2006). For example, offering onsite day care or promoting an integrating work climate during the recruitment process encourages integration at the workplace (Hochschild, 1997; Kossek, Noe, \& DeMarr, 1999). On the other hand, policies such as flexible schedules promote segmentation (Rothbard et al., 2005). Segmenting and integrating styles are most effective when individuals' boundary management preference and workplace policies are congruent (Rothbard et al., 2005). The alignment between what individuals prefer and perceive to get from their workplace is hence more important than the boundary management style per se (Kreiner, 2006), underling the importance of context.

Context influences, and restricts, how the work-family interface is managed (e.g., Allen, 2001; Anderson, Coffey, \& Byerly, 2002; Lapierre \& Allen, 2006; Voydanoff, 2005a). Supervisor behaviors are a particularly relevant aspect of context for employees. More specifically, family supportive supervisor behaviors (Hammer, Kossek, Yragui, Bodner, \& Hansen, 2009) facilitate the use of work-family policies by employees (Blair-Loy \& Wharton, 2004; Casper, Fox, Siztmann, \& Landy, 2004) and decrease work-family conflict (Frye \& Breaugh, 2004). Supervisors might also influence subordinates' ability to set their preferred levels of work-to-family interruption. Employees might work for managers who, by how they behave, signal to what extent they expect a certain level of work-to-family permeability. We argue that the level of the supervisor's work-to-family interruption signals and creates expectations for the subordinate's need to interrupt family 
time for work reasons. However, the supervisor's style might collide with the subordinate's permeability preferences and thus level of tolerance. When that misalignment happens negative consequences might follow.

\subsection{Person-Supervisor Fit and Atomistic-Objective Fit}

Individuals who fit the work environment are more satisfied with their job (Bretz \& Judge, 1994; Jansen \& Kristof-Brown, 2006), are more attached to their organization (Cable \& Judge, 1996; Westerman \& Cyr, 2004) and tend to perform better (Lauver \& Kristof-Brown, 2001; Wang, Zhan, McCune, \& Truxillo, 2011). A great deal of research has looked at the effects of fit between the person and his/her environment, whether this be the organization, the job or the workgroup (for a comprehensive review of older articles look at (Kristof, 1996). Person-Supervisor Fit (P-S fit) refers to the compatibility between subordinates and their supervisors. Researchers have explored dyadic leaderfollower types of fit such as: personality fit (Van Vianen et al., 2008; Zhang, Wang, \& Shi, 2012), values fit (Brown \& Trevifio, 2009; Meglino, Ravlin, \& Adkins, 1991) as well as the effects of the fit on specific values dimensions such as power distance (Cole, Carter, \& Zhen, 2013).

Paying attention to who assesses the source of information assessing the fit, and to whether fit is measured directly or indirectly, it can be classified as (Kristof, Zimmerman, \& Johnson, 2005): perceived fit, which refers to the direct assessment of fit by the individual; subjective fit, which refers to an indirect assessment of fit — that is $\mathrm{P}$ and $\mathrm{E}$ variables are rated separately - by the individual; and objective fit, which refers to an indirect assessment of fit by different parties. Studies of P-E fit are generally referred to as investigations of the same phenomenon regardless of whether they assess perceived, subjective or objective P-E fit (Kristof, 1996).

Edwards, Cabe, Williamson, Lambert, \& Shipp (2006) differ in their conceptualization of the types of fit and classify them as: atomistic, molecular and molar. In their words "Atomistic studies assess the perceived person and environment separately; molecular studies assess subjective P-E discrepancies that combine the person and environment but preserve the direction of their difference, and molar studies assess perceptions of P-E fit that combine the person and environment and disregard the direction of their difference, treating positive and negative discrepancies as equivalent in terms of P-E misfit" (p. 803). These two conceptualizations of the types of fit differ in their approach and overlap to a certain extent. Molar is equivalent to perceived fit, yet molar can be potentially rated by 
a third party; atomistic fit can be both objective and subjective; finally, Kristof and colleagues' (2005) typology does not refer to the molecular type of fit, which refers to direct assessment of misfit, i.e., discrepancy, and could potentially be rated by the individual or by a third party. This actually highlights that fit studies should specify to which type of fit refer so that they contribute to the nomological network. However, as Edwards and colleagues (2006) claim, most fit research treat all these phenomenon as if they were interchangeable, leaving many inconsistencies and holes in the nomological network. The present study will focus on the atomistic-objective fit, which has been under-studied as it is most difficult to measure.

There is some evidence that types of fit have different consequences, and potentially different antecedents. For instance, Turban and \& Jones (1988) investigate the consequences of molar-subjective supervisor-subordinate fit, atomistic-objective fit regarding important behaviors to receive merit pay raise and demographic similarity of individual characteristics. They found that although the three types of fit were related to subordinate performance, they differently predict job satisfaction and pay ratings. Hayibor, Agle, Sears, Sonnenfeld, \& Ward (2011) found that molar-perceived fit, i.e., followers' perceived value congruence between themselves (members of top management teams) and their leaders (CEOs), is positively related to followers' perceptions of the degree of charisma possessed by the leader. However, they found that results of atomistic-objective fit, i.e., the self-reported value of the supervisor and the self-reported value of the subordinate are measured separately and then a measure of value congruence is developed, has almost no influence to perceptions of charismatic leadership.

\section{3. (Mis)Alignment between Supervisor Interruption Behaviors and Subordinate Interruption Tolerance}

Research shows that supervisors shape subordinates' experiences. For instance, Cole, Bruch, \& Vogel (2006) show that amidst an organizational crisis, a subordinate's positive and negative emotions fully mediated the relationships between perceived supervisor support and cynicism, and a subordinate's psychological hardiness and cynicism. Eisenberger, Singlhamber, Vandenberghe, Sucharski, \& Rhoades (2002) demonstrate that when supervisors show support, subordinates perceive the entire organization as being more supportive, and this relationship is stronger the higher the supervisor is in the organizational hierarchy. In a time in which interdependence between supervisors and 
subordinates is becoming crucial for organizational performance, understanding the antecedents and consequences of (mis)alignment of supervisor-subordinate characteristics is more urgent. On the one hand, for subordinates, alignment might be important because they might be aware that their supervisors are subject to a similarity bias, and thus they want to comply with their expectations to be viewed in a more positive light. For instance, the experiment conducted by Deprez-Sims \& Morris (2010) found that decision makers have a bias against those perceived lower in similarity.

On the other hand, subordinates are subjected to role-sending signals from the supervisors, who communicate to their employees certain verbal and nonverbal cues regarding their expectations. Supervisors, acting as role senders, communicate expectations regarding role behavior to their subordinates pressuring them to comply with expectations (Greenhaus \& Powell, 2003). According to Greenhaus \& Powell (2003) supervisors might create stress when they expect subordinates to participate in a specific work activity while they participate in a family activity. The supervisor's (role sender) behaviors might therefore be strong cues that implicitly communicate role expectations. Similar to what happens with cultural values, supervisors' behaviors influence subordinates' values through "norming" and "conforming" regulatory effects of organizational values (Caprar \& Neville, 2012). The "norming" effects of supervisors' behaviors might shape what subordinates perceive as acceptable in terms, for instance, of hours worked and acceptable work-to-family interruptions. "Conforming" effects of managerial behaviors refers to the legitimizing consequences of those behaviors, for instance by making phone calls to home landlines, a form of work-to-family interruption, look legitimate.

To date, little is known regarding the effects of (mis)alignment between role-sender cues and the focal person's tolerance for interruption, leaving it unknown to what extent it matters, and to what extent researchers and practitioners alike should be concerned about, and therefore, act upon it. To fill this gap in the literature, our research focuses on the atomistic-objective fit of supervisors and subordinates. We consider supervisors and subordinates as separate entities and we collect data from two sources - self-reported levels of supervisor interruption behaviors from work to home and self-reported subordinate interruption tolerance coming from work to home - and study the effects of such alignment / misalignment on subordinates' well-being and engagement. We specifically focus on work-to-family interruptions because work-to-family and family-towork interruptions do not need to - and usually are not — equally matched (Kossek \& 
Lautsch, 2012) and, managerial work-to-family interruption behaviors are likely to signal to employees to what extent they are expected to act in a similar way. Specifically, when subordinates receive communications at non-work standard times, they'll notice that supervisors are working and probably interrupting their own family time. This will become a signal of what is expected and welcomed.

Supervisors could, to some extent, ameliorate this signaling effect by communicating, for instance, that they are not required to respond until they get to the office, or that the answer can wait to the next workday. However, even in cases where that signaling exists, research shows, and subordinates tend to know that supervisors prefer and tend to promote and evaluate in a more positive light, similar others, i.e., that supervisor and subordinate congruence in how they perceive the demands and characteristics of the work environment is linked to greater subordinate satisfaction and higher performance ratings (Turban \& Jones, 1988). Thus, supervisor interruption behaviors will still be relevant for the subordinate even if the supervisor clarifies the expectations about required responses to his/her interruptions.

Even though people might experience interruptions differently, interruption are a critical factor in job stress (Kirmeyer, 1988). Research shows that they are usually experienced negatively (Rogelberg, Leach, Warr, \& Burnfield, 2006), that they mediate the effect of objective work volume on the feeling of overload (Kirmeyer, 1988), and that work-related communications outside of regular work is associated with higher levels of work-tofamily conflict, distress and sleep problems (Schieman \& Young, 2013; Voydanoff, 2005). Although most research on interruptions refers to those happening in the work domain, mutatis mutandis, negative effects might occur when it is work that interrupts family time, i.e., that greater effort devoted to the care for the interruptions depletes the resources that could have been allocated to family; that progress toward completion of the primary task in the family role slows down; and that as a result the person feels increased fatigue and negative mood. In this study, we examine two individual outcomes, well-being and engagement.

\subsection{Well-being and Engagement in Work-Family Research}

Extensive empirical evidence demonstrates that experiences stemming from work and family roles affect individuals' well-being which involves simultaneous experience of high positive affect and low negative affect, and is related to good health (Wright, Cropanzano, \& Bonettet, 2007). In the work-family literature, well-being does not only 
refer to affective and physical dimensions but also embraces job satisfaction, marital satisfaction, family satisfaction and life satisfaction (Allen, Herst, Bruck, \& Sutton, 2000; Greenhaus, Bedeian, \& Mossholder, 1987). It has been shown consistently that role interference decreases well-being (e.g. Allen, et al., 2000; Thompson, Brough, \& Schmidt, 2006), whereas support systems stemming from families and the work environment (such as work supportive families and family friendly supervisor behaviors), protects it (Lapierre \& Allen, 2006; Mauno, 2010).

Engagement is a "persistent, positive affective motivational state of fulfillment in employees that is characterized by high vigor, dedication and absorption" (Maslach, Schaufeli, \& Leiter, 2001: 417). Vigor indicates high levels of energy and mental resilience while working and the willingness and ability to invest effort in one's work. Dedication denotes being strongly involved in one's work and experiencing a sense of significance, enthusiasm, inspiration, pride and challenge. Absorption means being fully concentrated and happily engrossed in one's work, whereby time passes quickly and one feels carried away by one's job. Engagement refers to a positive fulfilling work-related state of mind, which differs from organizational commitment and job involvement (Hallberg \& Schaufeli, 2006). While engaged individuals involved in extra work roles such as organizational citizenship behaviors experience higher work interference with family (Halbesleben, Harvey, \& Bolino, 2009), work engagement also facilitates workfamily relations via the sharing of positive work experiences at home (Culbertson, Mills, \& Fullagar, 2012). Research shows that perceived workplace flexibility is related to greater employee engagement (Pitt-Catsouphes \& Matz-Costa, 2008; Richman, Civian, Shannon, Hill, \& Brennan, 2008).

We expect that the alignment between supervisor interruption behaviors and subordinate interruption tolerance will lead to well-being and engagement. First, by the way supervisors behave subordinates will gather that their preferred boundary management style is acceptable. Second, subordinates will see themselves as similar to their supervisor. In addition, we expect that the alignment between supervisor interruption behaviors and subordinate interruption tolerance will be always experienced as more positive than the misalignment between interruption behaviors and tolerance. We also expect that more positive effects will follow when the alignment is at the extremes; i.e., when supervisors and subordinates are clearly inclined toward interruption behaviors and interruption tolerance, or toward no-interruption behaviors and interruption intolerance. Thus, we hypothesize that: 
Hypothesis 1. The more aligned a subordinate's tolerance for interruption is with his or her supervisor's level of interruption behavior (i.e., higher alignment) the higher the level of (a) well-being and (b) engagement of the subordinate.

Hypothesis 2. When alignment between the subordinate's tolerance for interruption and the supervisor's interruption behaviors is at high or low levels, subordinate's (a) well-being and (b) are higher than when alignment is at an intermediate level.

Although there are some scarce evidence that misalignment, for very specific outcomes and in very unique situations, might be beneficial (Roth, Kostova, \& Dakhli, 2011), it is generally accepted that misalignment is experienced negatively. Supervisors are role senders who, by interrupting their family time with work, signal to subordinates to what extent work should be allowed to intrude into family time. We can imagine a subordinate who most of the time he does not overlap with his supervisor's schedule. If he sees then that the supervisor contacts him, or others, while she is supposed to be at home, he'll know that the supervisor is interrupting her family time. The opposite case, in which the subordinate and the supervisor are most of the time working on the same schedule, the supervisor might actually interrupt the subordinate's, or any peer's, family time making it evident she is working after hours. One can easily imagine the strength of the message when supervisors send communications at atypical hours, during major national festivities or when they are supposedly on holidays. All these will be experienced more negatively when subordinate interruption tolerance is lower than supervisor interruption behaviors. On the other hand, when supervisors do not interrupt as much as the subordinate is willing to tolerate the interruption, the misalignment might be experienced positively. Thus, we propose that:

Hypothesis 3. Misalignment between the subordinate's tolerance for interruption and the supervisor's interruption behaviors are associated with a low level of subordinate's (a) well-being and (b) engagement.

Hypothesis 4. When supervisor's interruption behavior is higher than the subordinate's interruption tolerance, subordinate's (a) well-being and (b) 
engagement are lower than when supervisor's interruption behavior is lower than the subordinate's interruption tolerance.

\section{METHOD}

\subsection{Participants and Procedure}

Data were collected as a part of a larger project on work-family conciliation, yet none of the variables used in this paper have been used for other projects. Members of the International Work and Family Center (ICWC) from a Spanish university contacted two organizations located in El Salvador and invited them to participate in the study. In exchange, the companies were offered a complete analysis reporting the degree to which their work-family practices have been implemented and future steps that can be taken to improve (or sustain) their actual condition. In order to increase the response rate, we asked companies to sponsor our research and to let respondents complete the survey during their work-time. The survey was web-based and located on a secure server at the Spanish university.

In both organizations a supervisor headed each work unit. We distributed the surveys along with a cover letter assuring confidentiality and voluntary participation - to 101 supervisors and 952 subordinates. Among them, 85 supervisors (84.16\%) and 787 subordinates $(82.67 \%)$ returned the survey. We were able to match 582 supervisorsubordinate dyads, which represents an average span of control of 6.85 subordinates per supervisor. Among the final sample of supervisors, 30 were female (35.29\%), with an average age of 39.34 years (SD 8.12), and with an organizational tenure of 13.17 years (SD 7.92). Among the subordinates, 312 (53.61\%) were female, with an average age of 29.55 years (SD 8.39), and with an organizational tenure of 6.08 years (SD 5.85).

\subsection{Measures}

All the scales used in our survey were initially developed and validated in English but the survey was administered in Spanish. To ensure conceptual equivalence, we followed the approach suggested by Harkness and colleagues (2003). A bilingual researcher translated the questions into Spanish. This version was then back-translated into English by another bilingual researcher, and the back translation was compared with the English original. Revisions were made by a local country collaborator to ensure conceptual equivalence 
(Harzing, Reiche, \& Pudelko, 2013). All the scales were measured using a 7-point Likert scale in which $1=$ strongly disagree and $7=$ strongly agree.

Supervisor work-to-family interruption behaviors. We measured supervisor interruption behaviors using the four item scale developed by Kossek et al. (2012). This scale captures the extent to which individuals (supervisors) allow interruptions from one role to another (work-related issues outside work hours). A sample item of this scale is "I spend time and energies in work issues while I'm engaged in family or personal activities." In our study, this scale reported a reliability of .91 .

Subordinate work-to-family interruption tolerance. We measured subordinate interruption tolerance using a modified version of the four item scale developed by Kossek et al. (2012). In order to capture the preference for keeping both roles separate, i.e., the tolerance toward those interruptions, we added "I prefer not to" to every item of this scale before referring to interruption behaviors. A sample item of the modified scale is "I prefer not to spend time and energies in work issues while I'm engaged in family or personal activities." As we sought to test the alignment with supervisor interruption behaviors, we inverted the subordinates' responses in order to capture the work-to-family interruption tolerance (and not the intolerance). We inverted the responses by subtracting the subordinates' responses to eight because we measured this construct using a 7-point Likert scale. The reliability of this measure in our study is .85 .

Subordinate well-being. Subordinates responded to the three item well-being scale developed by Vansteenkiste and colleagues (2007). A sample item is "In general, I am satisfied with my life." The reliability of this measure in our study is .86 .

Subordinate engagement. Subordinates responded to the nine item engagement scale developed by Schaufeli and Bakker (2003). This scale measures three dimensions of engagement: vigor, dedication and absorption. In the present study, we found that the three dimensions were highly correlated (an average $r$ of .69). Therefore, we conducted an exploratory factor analysis (EFA) of the nine items representing the three dimensions and found only one factor with an eigenvalue greater than 1.0. Therefore, we created a single engagement index using the nine items of the scale. This is in line with previous research that also found that a single dimension fits the data better than the hypothesized 
three-dimension scale (e.g., Shimazu et al., 2008; Sonnentag, 2003). A sample item is " $A t$ my work, I feel bursting with energy." The reliability of this measure in our study is .91.

Control variables. Prior research suggests subordinate-level outcomes may be related to similarity in leader and follower demographic characteristics such as age and gender (e.g., Li \& Bagger, 2011; Perry, Kulik, \& Zhou, 1999). Therefore, following previous research, we controlled for the (dis)similarity in these variables in our analyses. Dissimilarity in age was operationalized as difference score between the leader and the follower (Perry, Kulik, \& Zhou, 1999). In the case of gender similarity, we used a dummy variable $(0=$ “different gender" and 1 = "same gender") (Li \& Bagger, 2011).

\subsection{Analysis}

Polynomial regressions. To test our hypotheses, involving alignment and asymmetrical misalignment effects, we used polynomial regressions and response surface modeling (Edwards \& Parry, 1993). We followed this procedure in the current analysis because it reduces methodological issues involved in difference scores (Edwards, 1994). Specifically, the dependent variables (well-being and engagement) were separately regressed on control variables as well as five polynomial terms. That is, subordinate interruption tolerance $(\mathrm{F})$, supervisor interruption behaviors $(\mathrm{L})$, subordinate interruption tolerance squared (F-squared), subordinate interruption tolerance times supervisor interruption behaviors (F x L), supervisor interruption behaviors squared (L-squared). To reduce multicollinearity and facilitate interpretation of the results, we scale-centered all the independent variables (Edwards \& Parry, 1993), which involved subtracting a value of four to our independent variables since all of them were measured on 7-point Likert scales.

After we performed the polynomial regressions, we plotted predicted values using the response surface technique for interpreting the results. These surfaces are shown in Figures 1 and 2, where well-being and engagement were graphically represented respectively - as a function of subordinate's work-to-family interruption tolerance and supervisor's work-to-family interruption behaviors. For building these graphical representations, we used the coefficients of the polynomial regressions as well as the postestimation covariance matrices as inputs (Shanock, Baran, Gentry, Pattison, \& Heggestad, 2010). Additionally, we used these inputs to examine the slopes and curvatures along two important lines - the alignment line and the misalignment line. 
The shape of the surface along alignment line is obtained by substituting the formula for this line $(\mathrm{F}=\mathrm{L})$ into the polynomial regression equation, including all the points where the subordinate's tolerance for interruption is matched with their supervisor's interruption behaviors. In Figures 1 and 2 the alignment line is from the front corner (where $F=\mathrm{L}=-3$ ) to the rear corner (where $\mathrm{F}=\mathrm{L}=3$ ). Similarly, the shape of the surface along the misalignment line is obtained by substituting the formula for this line $(\mathrm{F}=$ -L) into the polynomial regression equation, including all the points where the subordinate's tolerance and supervisor's behaviors are in perfect disagreement. In Figures 1 and 2 the misalignment line is from the left corner (where $\mathrm{F}=-3 ; \mathrm{L}=3$ ) to the right corner (where $\mathrm{F}=3 ; \mathrm{L}=-3$ ). For estimating these lines, their shape (curvature) and their respective significance we used the spreadsheet developed by Shanock and colleagues (2010) .

\section{RESULTS}

Table 1 shows the means, standard deviations, correlations, and reliability coefficients of the variables.

\begin{tabular}{|c|c|c|c|c|c|c|c|c|}
\hline Variable & Mean & SD & 1 & 2 & 3 & 4 & 5 & 6 \\
\hline 1 Age Difference & -8.488 & 9.132 & - & & & & & \\
\hline 2 Gender Similarity & .541 & .499 & $.100 *$ & - & & & & \\
\hline 3 Subordinate Prefernce for work-to Family Interruptions (F) & 3.456 & 1.925 & -.059 & .005 & .853 & & & \\
\hline 4 Subordinate Wellbeing & 6.073 & 1.258 & -.037 & .028 & $.134^{* *}$ & .860 & & \\
\hline 5 Subordinate Engagement & 5.691 & 1.192 & -.019 & .049 & $.198 * * *$ & $.694 * * *$ & .908 & \\
\hline 6 Supervisor Work-to-Family Interruptions (L) & 5.018 & 1.702 & .045 & -.044 & -.042 & $-.074 \dagger$ & $-.074 \dagger$ & .906 \\
\hline
\end{tabular}

Table 1. Means, standard deviations, correlations, and cronbach's alphas $(\mathrm{n}=582)$

\subsection{Construct Validity}

We conducted confirmatory factor analyses (CFAs) to examine the distinctiveness of the three subordinate self-reported variables (i.e., tolerance for work-to-home interruption, well-being, and engagement) doing maximum likelihood estimation in STATA 12 (StataCorp, 2011). We started by examining a 3-factor model where subordinate tolerance for integration, well-being and engagement, were each loaded onto separate factors. We compared this 3-factor model with 4 alternative models, including: (a) a 2-factor model where well-being and engagement loaded onto a single latent factor; (b) a 2-factor model where tolerance for interruptions and well-being loaded onto a single latent construct; (c) a 2-factor model where tolerance for integration and engagement loaded onto a single latent construct; and (d) a 1-factor model where all the items loaded onto a single latent factor. Results are summarized in Table 2. Overall, results of the confirmatory factor 
analysis revealed that the 3-factor model yielded a satisfactory fit [chi-square (99) $=$ $560.226 ; \mathrm{p}<.001 ; \mathrm{RMSEA}=.089, \mathrm{CFI}=.930, \mathrm{TLI}=.997, \mathrm{SRMR}=.035]$ and $\mathrm{a}$ significantly better fit than the alternative models. Therefore, the 3 subordinate-reported factors considered in our model were indeed distinct latent constructs.

\begin{tabular}{|c|c|c|c|c|c|c|c|c|c|c|}
\hline Model & Description & chi-square & $\mathrm{df}$ & RMSEA & CFI & TLI & SRMR & $\Delta$ chi-square & $\Delta \mathrm{df}$ & sig \\
\hline Model 1 & 3-factor model & 560.226 & 99 & 089 & .930 & .997 & .035 & & & \\
\hline Model 2 & 2-factor model & 603.128 & 101 & .092 & .924 & .910 & .037 & 42.90 & 2 & .000 \\
\hline Model 3 & 2-factor model & 1323.078 & 101 & .144 & .815 & .780 & .210 & 762.85 & 2 & .000 \\
\hline Model 4 & 2 -factor model & 1548.342 & 101 & .157 & .781 & .739 & .116 & 988.12 & 2 & .000 \\
\hline Model 5 & 1 -factor model & 1591.363 & 102 & .158 & .774 & .735 & .117 & 1031.14 & 3 & .000 \\
\hline
\end{tabular}

Notes: Comparisons were made with Model 1 .

RMSEA = root mean square error of approximation; $\mathrm{CFI}=$ comparative fit index; TLI = Tucker-Lewis index; SRMR $=$ standardized root mean square residual. Model 1: All 3 factors loading separately.

Model 2: Wellbeing and Engagement loaded onto a single latent factor

Model 3: Preference for Interrutions and Wellbeing loaded onto a single latent factor and Engagement loaded onto a single latent factor

Model 4: Preference for Interruptions and Engagement loaded onto a single latent factor and Weelbeing loaded onto a single latent factor

Model 5: All the items loaded onto a single latent factor.

Table 2. Confirmatory factor analysis of nested models $(n=582)$

\section{Hypotheses Testing}

\begin{tabular}{|c|c|c|c|c|c|}
\hline & Variables & \multicolumn{2}{|c|}{ Wellbeing } & \multicolumn{2}{|c|}{ Engagement } \\
\hline & Constant & 5.898 & $* * *$ & 5.541 & $* * *$ \\
\hline & Age Difference & -.003 & & -.001 & \\
\hline & Gender Similarity & .046 & & .086 & \\
\hline & Polinomial Terms & & & & \\
\hline$\beta 1$ & Subordinate Prefernce for work-to Family Interruptions $(\mathrm{F})$ & .104 & $* * *$ & .110 & $* * *$ \\
\hline$\beta 2$ & Supervisor work-to-Family Interruptions (L) & -.090 & ** & -.081 & * \\
\hline$\beta 3$ & F-Squared & .024 & & .014 & \\
\hline$\beta 4$ & $\mathrm{~F} \times \mathrm{L}$ & -.013 & & .011 & \\
\hline$\beta 5$ & L-Squared & .043 & * & .049 & $* *$ \\
\hline & R-squared & .038 & & .059 & \\
\hline & $F$ for the 3 quadratic terms: $\mathrm{F}(3,574)$ & 2.820 & $* *$ & 2.824 & $* *$ \\
\hline & Congruence Line (Sub=Sup) & & & & \\
\hline$\beta 1+\beta 2$ & Slope & .014 & & .029 & \\
\hline$\beta 3+\beta 4+\beta 5$ & Curvature & .054 & $\dagger$ & .074 & * \\
\hline & Incongruence Line (Sub=-Sup) & & & & \\
\hline$\beta 1-\beta 2$ & Slope & .193 & $* * *$ & .191 & $* * *$ \\
\hline$\beta 3-\beta 4+\beta 5$ & Curvature & .079 & $* *$ & .052 & $\dagger$ \\
\hline
\end{tabular}

The polinomial terms are unstandardized regression coefficients

$\dagger \mathrm{p}<.1, * \mathrm{p}<0.05, * * \mathrm{p}<0.01, * * * \mathrm{p}<0.001$

Table 3. Polynomial regression results predicting subordinate well-being and engagement $(\mathrm{n}=582)$

Hypothesis 1 predicted an alignment effect of subordinate tolerance for interruption and supervisor level of interruption behaviors such that the higher the alignment the higher the (a) well-being and (b) engagement. Table 3 presents the estimated coefficients as well as the slopes and curvatures along the congruence and incongruence lines for the polynomial regression predicting well-being. As shown in Table 3, the curvature of the 
congruence line is positive and significant $(.054 ; \mathrm{p}<.1)$ whereas the curvature of the incongruence line is positive and significant $(.079 ; \mathrm{p}<.01)$, suggesting that both lines are non-linear and convex (U-shaped). As mentioned above, the highest level of alignment is captured by the alignment line. The convex curvature along the misalignment line indicates that subordinate's well-being may be higher in some cases when deviating from the alignment line; thus, we do not find support for the alignment effect for the case of well-being. Similarly, Table 3 indicates that when predicting engagement the curvature of the alignment line is positive and significant $(.074 ; \mathrm{p}<.05)$, whereas the curvature of the misalignment line is positive and significant $(.052 ; \mathrm{p}<.1)$. The convex curvature along the misalignment line indicates that subordinate's engagement may be higher in some cases when deviating from the alignment line; thus, we do not find support for the alignment effect for the case of engagement. In sum, we do not find support for the alignment effect suggested in Hypothesis 1.

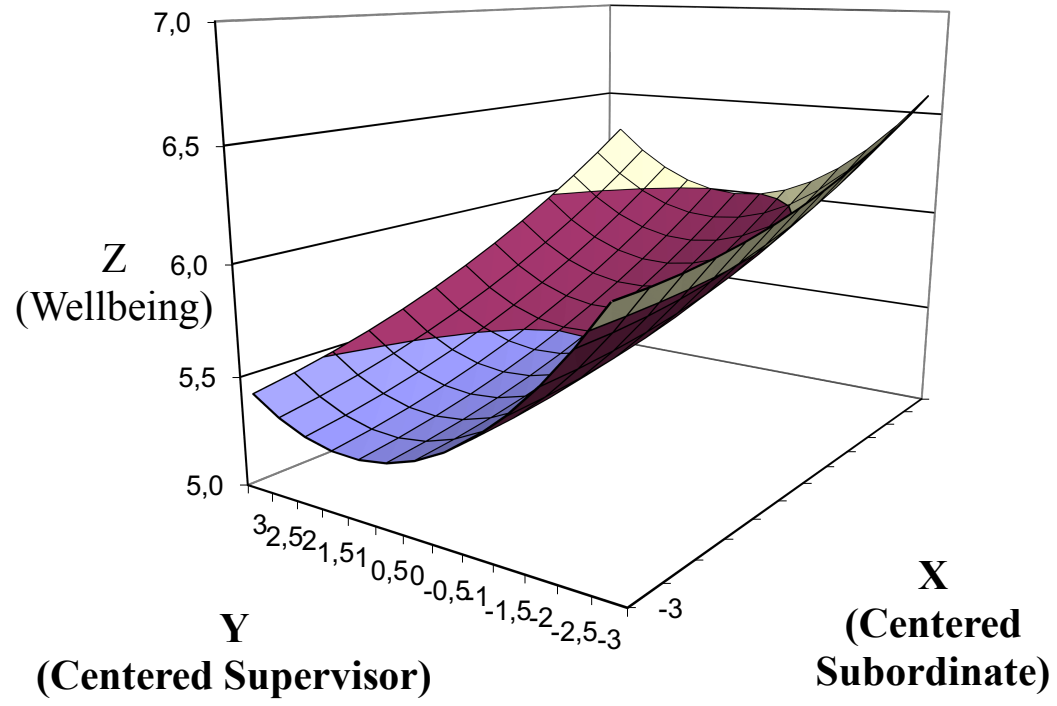

Figure 1. Well-being as predicted by work to family supervisor interruption behavior subordinate interruption tolerance

Hypotheses 2 predicted that (a) well-being and (b) engagement are higher when both the subordinate and supervisor are aligned at high or at low levels of interruption tolerance and behaviors, rather than when they are aligned at mid-levels of interruption tolerance and behaviors. As shown in Table 3, when predicting well-being, the slope along the alignment line is non-significant (.014; n.s.). Thus, we cannot conclude that well-being increases as the alignment takes place at higher levels of tolerance towards integration. Moreover, because the curvature of the alignment line is positive and significant (.054; 
$\mathrm{p}<.1$ ), well-being increases more sharply when the alignment takes place at more extreme points - when both the subordinate and supervisor are aligned at high or at low levels of interruption tolerance and behaviors. As shown in Figure 1, well-being is higher at high/high (rear corner) and low/low (front corner) alignments than at any point in between the alignment line. Similarly, as shown in Table 3, when predicting engagement, the slope along the alignment line is non-significant (.029; n.s.) and the curvature is positive and significant $(.074 ; p<.05)$. As shown in Figure 2, engagement increases more sharply when both the follower and leader are aligned at high (rear corner) or at low (front corner) levels of interruption tolerance and behaviors than in intermediate cases. Therefore, we find support for Hypothesis 2.

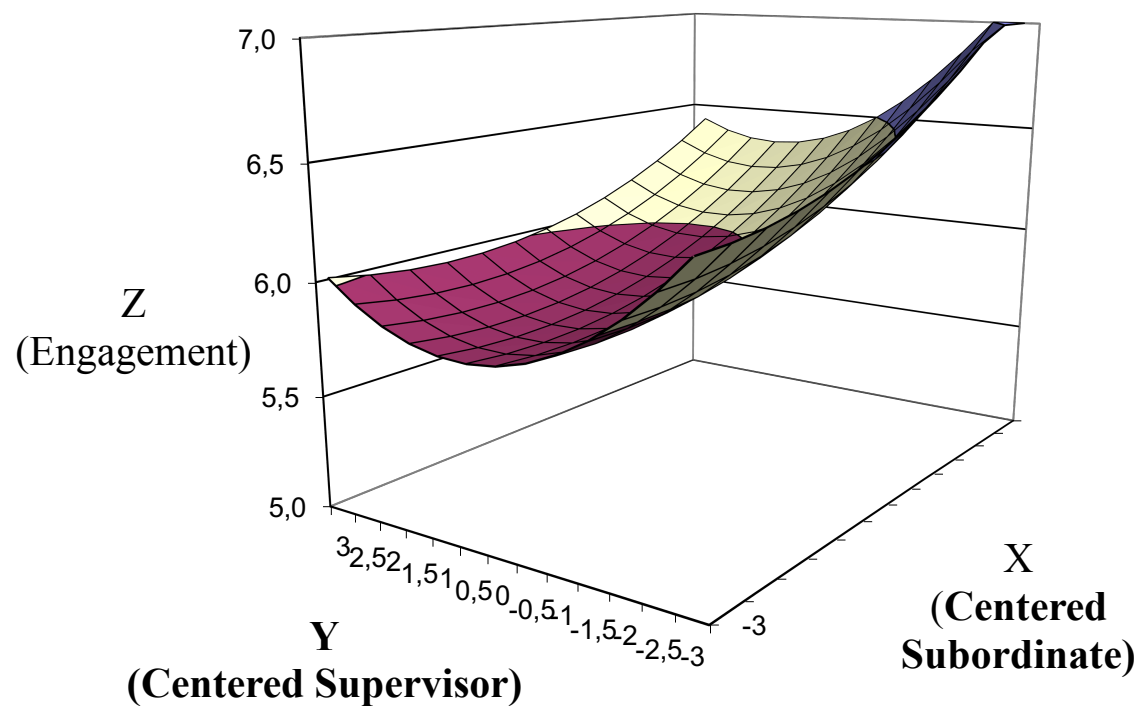

Figure 2. Engagement as predicted by work to family supervisor interruption behavior subordinate interruption tolerance

Hypothesis 3a predicted that the more misaligned a subordinate's level of interruption tolerance is with supervisor's level of interruption behaviors (i.e., higher misalignment), the lower the level of subordinate's well-being. As mentioned above, when predicting well-being the curvature of the misalignment line is positive and significant $(.079 ; \mathrm{p}<.01)$. A positive slope of the misalignment line (U-shaped) suggests that as the misalignment between the predictor variables (i.e., subordinate's interruption tolerance and supervisor's interruption behavior) increases, the outcome variable (i.e., well-being) increases rather than decreases (Shanock et al., 2010). Similarly for Hypothesis 3b, when predicting engagement the curvature of the misalignment line is also positive and significant (.052; $\mathrm{p}<.1$ ). In sum, although we find an effect of the size of the misalignment on our outcome 
variables, these results counter our expectations. Thus, we do not find support for Hypothesis 3.

In Hypothesis 4 we predicted an asymmetrical misalignment effect. More specifically, Hypothesis 4a predicted that the expected negative misalignment effect on well-being is lower when supervisor's interruption behaviors are higher than the subordinate's tolerance rather than when the subordinate's interruption tolerance is higher than the supervisor's behaviors. When predicting well-being the slope of the misalignment line is significant and positive $(.193 ; \mathrm{p}<.001)$, indicating that well-being is higher in the region where the subordinate's tolerance is higher than the supervisor's interruption behaviors (right side of the plot). Indeed, as seen in Figure 1 well-being is the highest in the right corner of the surface plot, where subordinate interruption tolerance is the highest while the supervisor interruption behavior is the lowest. This is also the case for Hypothesis $4 \mathrm{~b}$. When predicting engagement the slope of the misalignment line is positive and significant $(.191 ; \mathrm{p}<.001)$, which means that engagement is higher in the region where the employee's tolerance is higher than the supervisor's interruptive behaviors. This asymmetrical effect is also shown in Figure 2, in which engagement is lower at the left corner (where $\mathrm{F}=-3 ; \mathrm{L}=3$ ) than at the right corner (where $\mathrm{F}=3 ; \mathrm{L}=-3$ ). Therefore, we find support for Hypothesis 4.

\section{DISCUSSION}

The overall objective of this paper is to shed light on the alignment of subordinate's workto-family interruption tolerance and supervisor's work-to-family interruption behaviors, and assess the implications of (mis)alignment for subordinate's well-being and engagement. Our empirical study tests 582 supervisor-subordinate dyads and provides some interesting and surprising insights that may considerably advance knowledge in the work-family research area, and have implications for managerial practices.

\subsection{Integrating Expected and Unexpected Empirical Findings}

Based on boundary management and person-environment fit theories (Ashforth et al., 2000; Kristof, 1996; Nippert-Eng, 1996) we had postulated that alignment between subordinate interruption tolerance and supervisor interruption behaviors would have more positive relationships with employee well-being and engagement than misalignment (i.e., Hypothesis 1a and 1b). However, our findings indicate that such alignment is not always 
significantly better than the misalignment. On the contrary: testing Hypothesis $3 a$ and $3 b$, we showed that incongruence has a significant positive effect on well-being and engagement, rather than the hypothesized negative effect. These unexpected findings may indicate that the beneficial effects of congruence, or fit, between subordinates and supervisors on other dimensions such as values or personality (Brown \& Trevifio, 2009; Van Vianen et al., 2008), are more nuanced when considering the alignment between subordinate interruption tolerance and supervisor interruption behaviors. These results may also speak to some recent calls from researchers that have asked for examining congruence and incongruence effects separately, not assuming that congruence and incongruence are opposite ends of the same continuum, and not assuming that perceptions of the person and environment as separate entities (atomistic fit) are the same as directly assessing the difference (molecular) or the similarity (molar) between the person and the environment (Edwards et al., 2006).

Before examining the more nuanced explanations for this unexpected finding, we consider our further results. Based on our empirical tests analyzing the significance of the non-linear effects of alignment and the asymmetrical effects of misalignment in the response surface patterns (Edwards, 1994; Harris, Anseel, \& Lievens, 2008), we could confirm the remaining Hypotheses 2 and 4. Alignment between subordinate's tolerance and supervisor's behaviors that occurs at either high or low levels of interruptions, as compared to a medium level, is positively related to subordinate well-being and engagement (i.e., Hypothesis 2a and 2b). Misalignment where supervisor's interruption behaviors are higher than the subordinate's interruption tolerance is more detrimental for employee outcomes than a misalignment in which the subordinate's interruption tolerance is higher than the supervisor's actual interruption behaviors (i.e., Hypothesis $4 \mathrm{a}$ and $4 b)$.

Taken together, these findings suggest four scenarios that result in the best and worst consequences for employees' well-being and engagement. The first and best case scenario is when subordinate well-being and engagement are highest due to misalignment in which a subordinate has a high tolerance for interruptions and the supervisor reports low interruptive behaviors. In the scenarios that are second-best and third-best in terms of employee outcomes, subordinate tolerance and supervisor behaviors are aligned, i.e., about the same level. Finally, the fourth and worst scenario is when subordinate wellbeing and engagement are lowest due to misalignment in which subordinate has a low tolerance for interruptions and the supervisor displays high interruptive behaviors. For 
the scenarios two to four, the theorizing as put forward in the theory section of this paper provides a valid explanation. That is, supervisor-subordinate congruence signals to employees that their preferred style for boundary management, i.e., keeping work from intruding into family, is acceptable, and indicates a similarity between the subordinate's tolerance and the supervisor's behaviors. Such perceived acceptance and similarity in turn relates to a higher level of well-being and engagement.

\subsection{Integrated Theoretical Framework: Conservation of Resources Theory}

Our postulated theories, however, cannot integrate an explanation for our first scenario, suggesting that additional theory development is necessary. In particular, we propose that a self-regulation mechanism may underlie the effects for congruence. The Conservation of Resources $(\mathrm{CoR})$ theory outlines how people's responses to threatening or stressful situations can be explained by the resources they have available for coping with the situation (Hobfoll, 1989; Quinn, Spreitzer, Lam, 2012). Since the situation of balancing work-family demands, and especially handling interruptions, has often been identified as a potential stressor (Greenhaus \& Beutell, 1985), CoR theory seems applicable to understand our current question. Moreover, this theory does not contradict our theoretical reasoning as outlined before, but rather provides an underlying rationale for integrating this initial theorizing with our unexpected empirical findings (cf. Halbesleben, Wheeler, \& Rossi, 2012).

Based on CoR theory, we suggest that handling work-family interruptions is a situation for which people need resources to cope with — just as many other demanding situations at work ask for putting in resources — and that depletes energy (Hobfoll, 1989; Quinn, et al., 2012). Since people have an inherent tendency to conserve their energetic resources, they will strive to handle the situation in a way that requires the lowest possible level of resources (Quinn, et al., 2012). Prior research has indicated that employees can move resources between work and family domains, and that their boundary management strategies are consequential for the generation and depletion of resources (Halbesleben et al., 2012).

For the interaction between subordinate interruption tolerance and supervisor interruption behaviors, this implies that it is most beneficial when a subordinate has a high tolerance for interruptions (because with such high tolerance, dealing with interruptions will require a relatively low level of energy), and when a supervisor shows a low level of interruptive 
behavior (because no extra energy is required to deal with those interruptions). For example, when an employee does not mind that her supervisor interrupts family time, and yet this person observes that the supervisor hardly ever does so, the employee does not waste energy worrying about whether the supervisor will interrupt, and simultaneously since interruptions do not occur, she does not spend energies handling them. The worst possible scenario would be observed when a subordinate has a low tolerance for interruptions, and simultaneously the supervisor displays a high level of interruptive behaviors. In this case the expectation of interruptions stresses the employee, plus the actual handling of interruptions consumes his energies. These predictions are exactly what we observe in scenario 1 and 4.

Although the scenarios 2 and 3 could be understood from our original theorizing, they are also consistent with our integrated theorizing of CoR, boundary theory and fit theory. Because of the postulated benefits (i.e., acceptance and similarity) of congruence between employee preferences and supervisor behavior, we can theorize that a situation of congruence has energetic benefits. Employees enjoy such benefits, because they need to spend fewer resources on worrying about how their supervisor will perceive and judge them, as well as on potential impression management behaviors toward the supervisor. Such perceived energy benefits can in turn be expected to translate into higher well-being and engagement.

\section{IMPLICATIONS FOR PRACTICE}

Work and family have historically been regarded as "separate worlds" (Kanter, 1977; Pleck, 1976). However, our results show that they are more inter-connected than one would expect, i.e., even the way managers' operate in their "non-work time" affects employees' well-being and engagement. This indicates that supervisors' use of their spare time has a symbolic affect on employees, and that they should know they are role senders even when they work away from work space and time. Managers' work from non-work spaces and times might thwart — or foster — employees' ability to manage their own work-family interface, and in turn their well-being and engagement.

Our results suggest that companies might benefit from having clear HR policies that help in reducing employees' uncertainties about what is "acceptable" behavior in terms of contacting others and making it visible that people are working. This should specially target managers, so that they understand when, and to what extent, it is acceptable to 
make visible that they work at non-work standard hours. Managers should know the consequences that their behaviors might have on others, imposing burdens that show to actually be detrimental for the company. There are companies that are doing things that might help in this regard: like programming emails so that even if they are written at nonwork hours they reach the target person at work-hours.

Finally, our results suggest that even when employees clearly tolerate interruptions, they are much better off if they are not interrupted. Thus, training employees to raise their tolerance might be a good option that will give the best results if later the employee is not interrupted.

\section{LIMITATIONS AND FUTURE RESEARCH}

The limitations of our study come from different sources. First, potential limitations to the external validity of our results come from the sample of subordinates belonging to two organizations from the service sector located in only one country (El Salvador). Due to particular national characteristics that might affect such results, any study done in only one country calls for caution when generalizing the results. More specifically, El Salvador is characterized by being culturally high in power distance (Hofstede, 2001). Researchers have proposed that in such cultures congruence effects might be higher because subordinates tend to monitor more the supervisor's characteristics and working styles and align to them (Zhang et al., 2012). In our study this would imply that congruence would have had a stronger effect on outcomes compared to people from countries lower in power distance orientation. However, our findings show that actually misalignment may play a more important role than alignment, so that a bias toward congruence is not a concern in our data. Taking into account the influence of culture on how people manage the worklife interface (Powell, Francesco, \& Ling, 2009), future research should look into the role of specific dimensions of culture, or other national context variables, on the impact of alignment of subordinate's tolerance for work-to-family interruptions and supervisor's actual work-to-family interruption behaviors. This would facilitate a more nuanced understanding of our findings.

Second, the cross-sectional nature of our data might, to some extent, prevent us from making conclusions about causality. However, this is not such a concern in fit studies, in which both components of the fit may vary as a function of time in non-equivalent ways, 
rendering cross sectional designs less susceptible to spurious results than in other types of research (Lee \& Antonakis, in press).

Third, although related to the previous one, the work units surveyed in our study were established before we gathered the data. According to the ASA - attraction-selectionattrition — model (Schneider, 1987; Schneider, Goldstein, \& Smith, 1995), workgroups and organizations become more homogeneous over time, thus it might be that those employees who perceive that their supervisors interrupt more than they are willing to tolerate abandoned the organizations before we gathered the data. However, if this is the case, homogeneity would convey that our data might be biased toward subordinates with higher tolerance for interruptions, so the fact that we still find significant results suggests that our findings are rather conservative. 


\section{REFERENCES}

Allen T. D. (2001). Family supportive work environments: The role of organizational perceptions. Journal of Vocational Behavior, 58: 414-35.

Allen, T. D., Herst, D. E., Bruck, C. S., \& Sutton, M. (2000). Consequences associated with work-to-family conflict: A review and agenda for future research. Journal of Occupational Health Psychology, 5: 278-308.

Ashforth, B. E., Kreiner, G. E., \& Fugate, M. (2000). All in a day's work: Boundaries and micro role transitions. Academy of Management Review, 25(3): 472-491.

Anderson, S. E., Coffey, B. S., \& Byerly, R. T. (2002). Formal organizational initiatives and informal workplace practices: Links to work-family conflict and job-related outcomes. Journal of Management, 28(6): 787-810.

Blair-Loy, M. \& Wharton, A. S. (2004). Organizational commitment and constraints on work-family policy use: Corporate flexibility policies in a global firm. Sociological Perspectives, 47(3), 243-267.

Bourhis, A., \& Mekkaoui, R. (2010). Beyond work-family balance: Are family-friendly organizations more attractive? Industrial Relations, 65(1): 98-117.

Bretz, R.D., \& Judge, T. A. (1994). Person-Organization Fit and the theory of work Adjustment: Implications for satisfaction, tenure, and career success. Journal of Vocational Behavior, 44(1):32-54.

Brown, M. E., \& Trevifio, L. K. (2009). Leader-follower values congruence: Are socialized charismatic leaders better able to achieve it? Journal of Applied Psychology, 94(2): 478-490.

Cable, D. M., \& DeRue, D. S. (2002). The convergent and discriminant validity of subjective fit perceptions. Journal of Applied Psychology, 87(5): 875-884.

Cable, D. M., \& Judge, T. A. (1996). Person-Organization Fit, job choice decisions, and organizational entry. Organizational Behavior and Human Decision Processes, 67(3): 294-311.

Caprar, D., \& Neville, B. (2012). 'Norming' and 'conforming': Integrating cultural and institutional explanations for sustainability adoption in business. Journal of Business Ethics, 110(2): 231-245.

Casper, W. J., Fox, K. E., Sitzmann, T. M., \& Landy, A. L. (2004). Supervisor referrals to work-family programs. Journal of Occupational Health Psychology, 9: 136-151.

Chinchilla, N., Las Heras, M., \& Masuda, A. D. (2009). No matter where you are: A practical guide for implementing effective work family policies across countries. Amherst, MA: HRD Press, Inc. 
Clark, S. C. (2000). Work / Family boarder theory: A new theory of work / family balance. Human Relations. 53: 747-770.

Cole, M. S., Bruch, H., \& Vogel, B. (2006). Emotion as mediators of the relations between perceived supervisor support and psychological hardiness on employee cynicism. Journal of Organizational Behavior, 27(4): 463-484.

Cole, M. S., Carter, M. Z., \& Zhen, Z. (2013). Leader-team congruence in power distance values and team effectiveness: The mediating role of procedural justice climate. Journal of Applied Psychology, 98(6): 962-973.

Culbertson, S. S., Mills, M., \& Fullagar, C. J. (2012). Work engagement and work-family facilitation: Making homes happier through positive affective spillover. Human Relations, 65(9): 1155-1177.

Deprez-Sims, A.-S., \& Morris, S. B. (2010). Accents in the workplace: Their effects during a job interview. International Journal of Psychology, 45(6): 417-426.

Edwards, J. R. (1994). The study of congruence in organizational behavior research: Critique and a proposed alternative. Organizational Behavior and Human Decision Processes, 58(1): 51-100.

Edwards, J. R., Cabe, D. M., Williamson, I. O., Lambert, L. S., \& Shipp, A. J. (2006). The phenomenology of fit: Linking the person and environment to the subjective experience of person-environment fit. Journal of Applied Psychology, 91(4): 802-827.

Edwards, J. R., \& Parry, M. E. (1993). On the use of polynomial regression equations as an alternative to difference scores in organizational research. Academy of Management Journal, 36(6): 1577-1613.

Eisenberger, R., Singlhamber, F., Vandenberghe, C., Sucharski, I., \& Rhoades, L. (2002). Perceived supervisor support: Contributions to perceived support and employee retention. Journal of Applied Psychology, 87: 565-573.

Frye, N. K., \& Breaugh, J. A. (2004). Family-friendly policies, supervisor support, workfamily conflict, family-work conflict, and satisfaction: A test of a conceptual model. Journal of Business and Psychology, 19(2): 197-220.

Greenhaus, J. H. Bedeian, A. G. \& Mossholder, K. W. (1987). Work experiences, job performance, and feelings of personal and family well-being. Journal of Vocational Behavior, 31(2): 200-215.

Greenhaus, J. H., \& Beutell, N. J. (1985). Sources of conflict between work and family roles. Academy of Management Review, 10(1): 76-88.

Greenhaus, J. H., \& Powell, G. N. (2003). When work and family collide: Deciding between competing role demands. Organizational Behavior and Human Decision Processes, 90(2): 291-303. 
Halbesleben, J.R.B., Harvey, J., \& Bolino, M.C. (2009). Too engaged? A Conservation of Resources view of the relationship between work engagement and work interference with family. Journal of Applied Psychology, 94: 1452-1465.

Halbesleben, J. R., Wheeler, A. R., \& Rossi, A. M. (2012). The costs and benefits of working with one's spouse: A two-sample examination of spousal support, work-family conflict, and emotional exhaustion in work-linked relationships. Journal of Organizational Behavior, 33(5): 597-615.

Hallberg, U. E. \& Schaufeli, W. B. (2006). Same same but different? Can work engagement be discriminated from job involvement and organizational commitment? European Psychologist, 11(2): 119-127.

Hammer, L. B., Kossek, E. E., Yragui, N. L., Bodner, T. E., \& Hanson, G. C. (2009). Development and Validation of a Multidimensional Measure of Family Supportive Supervisor Behaviors (FSSB). Journal of Management, 35(4): 837-856.

Harkness, J. A., Van de Vijver, F. J., \& Mohler, P. P. (2003). Cross-cultural survey methods. Hoboken, NJ: John Wiley \& Sons, Inc.

Harris, M. M., Anseel, F., \& Lievens, F. (2008). Keeping up with the Joneses: A field study of the relationships among upward, lateral, and downward comparisons and pay level satisfaction. Journal of Applied Psychology, 93(3): 665-681.

Harzing, A. W., Reiche, B. S., \& Pudelko, M. (2013). Challenges in international survey research: A review with illustrations and suggested solutions for best practice. European Journal of International Management, 7(1): 112-134.

Hayibor, S., Agle, B., Sears, G., Sonnenfeld, J., \& Ward, A. (2011). Value congruence and charismatic leadership in CEO-top manager relationships: An empirical investigation. Journal of Business Ethics, 102(2): 237-254.

Hecht, T. D., \& Allen, N. J. (2009). A longitudinal examination of the work- nonwork boundary strength construct Journal of Organizational Behavior, 30: 839-862.

Hobfoll, S. E. (1989). Conservation of resources: A new attempt at conceptualizing stress. American Psychologist, 44(3): 513-524.

Hochschild, A. R. (1997). The time bind: When work becomes home and home becomes work. NY: Henry Holt and Company, LLC.

Hofstede, G. H. (2001). Culture's consequences: Comparing values, behaviors, institutions and organizations across nations (2nd ed.). Thousand Oaks, CA: Sage.

Jansen, K.J. \& Kristof-Brown, A. (2006). Toward a multidimensional theory of PersonEnvironment Fit. Journal of Managerial Issues, 18(2): 193-212.

Kanter, R. M. (1977). Work and family in the United States: A critical review and agenda for research and policy. New York: Russell Sage Foundation. 
Kirmeyer, S. L. (1988). Coping with competing demands: Interruption and the type A pattern. Journal of Applied Psychology, 73(4): 621-629.

Kossek, E. E., \& Lautsch, B. A. (2008). CEO of Me: Creating a Life That Works in the Flexible Job Age. Philadelphia, PA: Wharton School Publishing.

Kossek, E. E., \& Lautsch, B. A. (2012). Work-family boundary management styles in organizations: A cross-level model. Organizational Psychology Review, 2: 152-171.

Kossek, Noe, \& DeMarr, (1999). Work-family role synthesis: Individual and organizational determinants. International Journal of Conflict Management, 10(2): 102129.

Kossek, E. E., Ruderman, M. N., Braddy, P. W., \& Hannum, K. M. (2012). Worknonwork boundary management profiles: A person-centered approach. Journal of Vocational Behavior, 81(1): 112-128.

Kreiner, G. E. (2006). Consequences of work-home segmentation or integration: A person-environment fit perspective. Journal of Organizational Behaviour, 27: 485-507.

Kreiner, G. E., Hollensbe, E. C., \& Sheep, M. L. (2009). Balancing borders and bridges: Negotiating the work-home interface via boundary work tactics. Academy of Management Journal, 52(4): 704-730.

Kristof, A. L. (1996). Person-organization fit: An integrative review of its conceptualizations, measurement, and implications. Personnel Psychology, 49: 1-49.

Kristof, A. L., Zimmerman, R. D., \& Johnson, E. C. (2005). Consequences of individuals' fit at work: A meta-analysis of Person-Job, Person-Organization, Person-group, and Person-Supervisor Fit. Personnel Psychology, 58: 281-342.

Lapierre, L. M., \& Allen, T. D. (2006). Work-supportive family, family-supportive supervision, use of organizational benefits, and problem-focused coping: Implications for work-family conflict and employee well-being. Journal of Occupational Health Psychology, 11(2), 169-181.

Lauver, K. J. \& Kristof-Brown, A. (2001). Distinguishing between employees' perceptions of Person-Job and Person-Organization Fit. Journal of Vocational Behavior, 59(3): 454-470.

Lee, Y. T., \& Antonakis, J. (2012). In press. When preference is not satisfied but the individual is: How power distance moderates person-job fit. Journal of Management.

Li, A., \& Bagger, J. (2011). Walking in your shoes: Interactive effects of child care responsibility difference and gender similarity on supervisory family support and workrelated outcomes. Group \& Organization Management, 36(6): 659-691.

Maslach, C., Schaufeli, W.B., \& Leiter, M.P. (2001). Job burnout. Annual Review of Psychology, 52: 397-422. 
Matthews, R. A. \& Barnes-Farrell, J. L. (2010). Development and initial evaluation of an enhanced measure of boundary flexibility for the work and family domains. Journal of Occupational Health Psychology, 15(3): 330-346.

Mauno, S. (2010). Effects of work-family culture on employee well-being: Exploring moderator effects in a longitudinal sample. European Journal of Work and Organizational Psychology, 19(6): 675-695.

Meglino, B. M., Ravlin, E. C., \& Adkins, C. L. (1991). Value congruence and satisfaction with a leader: An examination of the role of interaction. Human Relations, 44(5): 481495.

Nippert-Eng, C. E. (1996). Home and work: Negotiating boundaries through everyday life. Chicago: University of Chicago Press.

Perry, E. L., Kulik, C. T., \& Zhou, J. (1999). A closer look at the effects of subordinatesupervisor age differences. Journal of Organizational Behavior, 20(3): 341-357.

Pitt-Catsouphes, M., \& Matz-Costa, C. (2008). The multi-generational workforce: Workplace flexibility and engagement. Community, Work \& Family, 11(2): 215-229.

Pleck, E. H. (1976). Two worlds in one: Work and family. Journal of Social History: 10th Anniversary Issue: Social History Today and Tomorrow?, 10(2): 178-195.

Poelmans, S. A. Y., Greenhaus, J., \& Maestro, M. L. H. (2013). Expanding the boundaries of work-family research: A vision for the future. New York: Palgrave Macmillan.

Powell, G. N., Francesco, A. M., \& Ling, Y. (2009). Toward culture-sensitive theories of the work-family interface. Journal of Organizational Behavior, 30(5): 597-616.

Quinn, R. W., Spreitzer, G. M., \& Lam, C. F. (2012). Building a sustainable model of human energy in organizations: Exploring the critical role of resources. The Academy of Management Annals, 6(1): 337-396.

Richman, A. L. Civian, J. T. Shannon, L. L. Hill, E. J. \& Brennan, R. T. (2008). The relationship of perceived flexibility, supportive work-life policies, and use of formal flexible arrangements and occasional flexibility to employee engagement and expected retention. Community, Work \& Family, 11(2): 183-197.

Rogelberg, S. G., Leach, D. J., Warr, P. B., \& Burnfield, J. L. (2006). "Not another meeting!" Are meeting time demands related to employee well-being? Journal of Applied Psychology, 91(1): 83-96.

Roth, K., Kostova, T., \& Dakhli, M. (2011). Exploring cultural misfit: Causes and consequences. International Business Review, 20(1): 15-26.

Rothbard, N. P., Phillips, K. W., \& Dumas, T. L. (2005). Managing multiple roles: Workfamily policies and individuals' desires for segmentation. Organization Science, 16(3): 243-258. 
Schaufeli, W. B., Bakker, A. B. (2003). UWES-utrecht work engagement scale: test manual. Unpublished Manuscript: Department of Psychology, Utrecht University.

Schieman, S., \& Young, M. C. (2013). Are communications about work outside regular working hours associated with work-to-family conflict, psychological distress and sleep problems?. Work \& Stress, 27(3): 244-261.

Schneider, B. (1987). The people make the place. Personnel Psychology, 40(3): 437.

Schneider, B., Goldstein, H. W., \& Smith, B. D. (1995). The ASA framework: An update. Personnel Psychology, 48(4): 747-773.

Shanock, L. R., Baran, B. E., Gentry, W. A., Pattison, S. C., \& Heggestad, E. D. (2010). Polynomial regression with response surface analysis: A powerful approach for examining moderation and overcoming limitations of difference scores. Journal of Business and Psychology, 25(4): 543-554.

Shimazu, A., Schaufeli, W. B., Kosugi, S., Suzuki, A., Nashiwa, H., Kato, A., \& Goto, R. (2008). Work engagement in Japan: validation of the Japanese version of the Utrecht Work Engagement Scale. Applied Psychology: An International Review, 57(3): 510-523.

Sonnentag, S. (2003). Recovery, work engagement, and proactive behavior: A new look at the interface between nonwork and work. Journal of Applied Psychology, 88(3): 518528.

StataCorp. (2011). Stata Statistical Software: Release 12. College Station, TX: StataCorp LP.

Sweet, S. (2014). The work-family interface: An introduction. Thousand Oaks, CA: SAGE Publications, Incorporated.

Thompson, B. M., Brough, P. A. \& Schmidt, H. (2006). Supervisor and subordinate workfamily values: Does similarity make a different. International Journal of Stress Management, 13(1): 45-63.

Turban, D. B., \& Jones, A. P. (1988). Supervisor-subordinate similarity: Types, effects, and mechanisms. Journal of Applied Psychology, 73(2): 228-234.

Van Vianen, A. M., Nijstad, B. A., \& Voskuijl, O. F. (2008). A person-environment fit approach to volunteerism: Volunteer personality fit and culture fit as predictors of affective outcomes. Basic \& Applied Social Psychology, 30(2): 153-166.

Vansteenkiste, M., Neyrinck, B., Niemiec, C. P., Soenens, B., Witte, H., \& Broeck, A. (2007). On the relations among work value orientations, psychological need satisfaction and job outcomes: A self-determination theory approach. Journal of Occupational and Organizational Psychology, 80(2): 251-277. 
Voydanoff, P. (2005). Consequences of boundary-spanning demands and resources for work-to-family conflict and perceived stress. Journal of Occupational Health Psychology, 10(4): 491-503.

Wang, M. O., Zhan, Y., McCune, E., \& Truxillo, D. (2011). Understanding newcomers' adaptability and work-related outcomes: Testing the mediating roles of perceived P-E fit variables. Personnel Psychology, 64(1): 163-189.

Westerman, J. W., \& Cyr, L. A. (2004). An integrative analysis of Person-Organization Fit theories. International Journal of Selection and Assessment, 12(3):252-261.

Wright, T. A., Cropanzano, R., \& Bonett, D. G. (2007). The moderating role of employee positive well-being on the relation between job satisfaction and job performance. Journal of Occupational Health Psychology, 12: 93-104.

Zhang, Z., Wang, M. O., \& Shi, J. (2012). Leader-follower congruence in proactive personality and work outcomes: The mediating role of leader-member exchange. Academy of Management Journal, 55(1): 111-130. 